\title{
The specific killing effect of matrine on castration-resistant prostate cancer cells by targeting the Akt/FoxO3a signaling pathway
}

\author{
SHOUMIN BAI ${ }^{1,3^{*}}$, TING CHEN $^{1,3^{*}}$, XIAOLI YU ${ }^{1}$, MING LUO $^{1}$, XIANJU CHEN ${ }^{2,3}$, \\ CHUNHAO LIN $^{2,3}$, YIMING LAI ${ }^{2}$ and HAI HUANG ${ }^{2,3}$ \\ Departments of ${ }^{1}$ Radiation Oncology and ${ }^{2}$ Urology, and ${ }^{3}$ Guangdong Provincial Key Laboratory of \\ Malignant Tumor Epigenetics and Gene Regulation, Sun Yat-Sen Memorial Hospital, \\ Sun Yat-Sen University, Guangzhou 510120, P.R. China
}

Received December 1, 2016; Accepted January 26, 2017

DOI: $10.3892 /$ or.2017.5510

\begin{abstract}
Matrine, a Sophora alkaloid, exhibits antiproliferative and anti-carcinogenic activities through several mechanisms. In a previous study, we found that matrine could effectively inhibit the proliferation of castration-resistant prostate cancer (CRPC). In the present study, the effect of matrine and LY294002 on the expression of the Akt/FoxO3a signaling pathway was examined by western blot analyses and RT-PCR. We discovered that matrine significantly inhibited the proliferation of both prostate cancer cell line PC-3 and prostate epithelial cell line RWPE1, induced apoptosis and induced cell cycle arrest. In addition, LY294002 was found to enhance the effect of matrine. Furthermore, the effects of matrine on the inhibition of proliferation and the induction of cell cycle arrest and cell apoptosis were more effective on PC-3 than on RWPE1 cells. Compared to RWPE1 cells, matrine exerted a more powerful influence on PC-3 cells in increasing the expression of the relevant protein. Our data suggested that FoxO3a-Bim and FoxO3a-P27 may mediate matrine-inhibited proliferation of CRPC cells by activating cell apoptosis and inducing cell cycle arrest. Matrine exhibited high selectivity in killing CRPC cells. Our findings demonstrated that matrine could be used in a potential therapeutic role in the management of CRPC in humans.
\end{abstract}

\section{Introduction}

Prostate cancer is the most common cancer of the male urogenital system and the second leading cause of cancer-related

Correspondence to: Professor Hai Huang or Dr Yiming Lai, Department of Urology, Sun Yat-Sen Memorial Hospital, Sun Yat-Sen University, 107 Yanjiang West Road, Guangzhou 510120, P.R. China

E-mail: huanghai257@126.com

E-mail: laiyim@qq.com

${ }^{*}$ Contributed equally

Key words: matrine, castration-resistant prostate cancer, FoxO3a, apoptosis, cell cycle arrest mortality in the US. It remains the leading cause of new cancer cases among men, accounting for $26 \%$ of the new cases diagnosed in $2015(1,2)$. Asian countries have a substantially lower incidence of prostate cancer, but a higher proportion of advanced-stage or metastatic prostate cancer (3). For patients with early-stage prostate cancer, androgen is the major regulator of cellular proliferation. Nevertheless, $70-80 \%$ of androgen-independent prostate cancer patients have no curative treatment options. Therefore, there is a need to explore more effective anti-prostate cancer drugs and therapeutic approaches.

The phosphoinositide-3 kinase/protein kinase B (PI3K/Akt) cell proliferation and survival signaling pathway plays a significant role in tumorigenesis in numerous types of cancer. Dysregulation of the PI3K pathway commonly occurs in prostate carcinogenesis (4). Fork head box O (FOXO) transcription factor contains four members, FoxO1 (FKHR), FoxO3a (FKHRL1), FoxO4 (AFX) and FoxO6, which function downstream of the PI3K/Akt signaling pathway. FOXO proteins primarily function as transcription factors in the nucleus by regulating the expression of a large spectrum of tumor-suppressor genes. Specifically, FoxO3a plays an important role in multiple cellular processes including cell cycle arrest, cell death, DNA damage repair, stress resistance and metabolism (5). Several anticancer drugs, including imatinib, paclitaxel and doxorubicin, have been found to increase FoxO3a by preventing oncogenic suppression of the protein functions of FOXO (6). In a previous study, during prostate cancer progression, increasing Akt activation led to an increase in p-FoxO3a, and induced an increase in cytosolic accumulation of FoxO3a, and binding with 14-3-3 (a chaperone protein), which potentially affected transcriptional activity in an age-dependent manner. Accumulated cytosolic FoxO3a is correlated to Ser253 phosphorylation and accounts for FoxO3a nuclear exclusion; these events lead to the regulation of FOXO-targeted genes, such as pro- and anti-apoptotic proteins, and cell cycle regulatory proteins $(7,8)$.

Matrine, a major component extracted from a traditional Chinese herb (Sophora flavescens), has a wide range of clinical applications including cardiovascular protection, anti-viral 
therapy for hepatitis and anti-inflammatory activity in neuropathic pain $(9,10)$. No apparent side-effects or toxicity of matrine have been reported. Recently, the anticancer effect of matrine has been explored, for instance, in gastric (11), breast (12) and cervical cancer (13). Its mechanisms against various types of cancers include inducing cell cycle arrest, suppressing invasion and metastasis, restraining angiogenesis, accelerating apoptosis, inducing differentiation, reversing multi-drug resistance and preventing or decreasing chemotherapy- or radiotherapy-induced toxicity (14). However, a systematic scientific evaluation of matrine and its anticancer mechanisms in prostate cancer cell lines remains to be performed.

\section{Materials and methods}

Cell lines, cell culture and chemicals. Prostate epithelial cells RWPE1 and androgen-independent prostatic carcinoma cells (PC-3) were used in the present study. The PC-3 cell line was obtained from the Center for Experimental Animals of Sun Yat-Sen University. The cells were maintained in RPMI-1640 medium (Gibco, Grand Island, NY, USA) with $10 \%$ fetal bovine serum (FBS), supplemented with $1 \%$ penicillin and streptomycin (Invitrogen, Carlsbad, CA, USA). The RWPE1 cell line was maintained in complete keratinocyte serum-free medium, supplemented with $50 \mathrm{mg} / \mathrm{ml}$ of bovine pituitary extract and $5 \mathrm{ng} / \mathrm{ml}$ of epidermal growth factor (Gibco). Both cell lines were cultured in a humidified incubator at $37^{\circ} \mathrm{C}$ with an atmosphere of $5 \% \mathrm{CO}_{2}$. Matrine was purchased from Melonepharma (Dalian, Liaoning, China). LY294002 was purchased from Cell Signaling Technology (Carlsbad, CA, USA) and was dissolved in dimethyl sulfoxide (DMSO) according to the manufacturer's instructions. Antibodies against Akt, p-Akt, P27,CDK4 and Bim were purchased from Cell Signaling Technology. Antibodies against $\mathrm{CDK} 2$, Bax, Bcl-2 and p-FoxO3a were purchased from Abcam (Cambridge, MA, USA). Antibodies against FoxO3a were purchased from GeneTex (Irvine, CA, USA).

Cell proliferation assay. The cell proliferation rate was determined using an MTS assay (Promega Biosciences, LLC, San Luis Obispo, CA, USA) according to the manufacturer's protocol. Briefly, $5 \times 10^{3}$ cells/well were seeded into 96 -well plates (Corning, New York, NY, USA) containing $100 \mu \mathrm{l}$ of culture medium plus different concentrations of matrine and were grown at $37^{\circ} \mathrm{C}$ for 24,48 and $72 \mathrm{~h}$. Subsequently, the MTS reagent was added to each well and incubated in the dark for $2 \mathrm{~h}$ and optical densities (ODs) at $490 \mathrm{~nm}$ (OD490) were determined using a microplate reader (Multiskan MK3; Thermo Scientific, Shanghai, China).

Cell apoptosis assay. The Annexin V-FITC/propidium iodide (PI) apoptosis detection kit (eBioscience, Inc., San Diego, CA, USA) was used to detect cell apoptosis according to the instructions of the manufacturer. Cells were seeded into 6 -well plates at $1.5 \times 10^{5}$ cells/well in a medium supplemented with $10 \%$ FBS for $24 \mathrm{~h}$, followed by the addition of matrine (1.5 g/l), LY294002 (10 $\mu \mathrm{mol} / \mathrm{l})$ or a combination of the two. After $48 \mathrm{~h}$, treated cells were collected and washed twice with chilled phosphate-buffered saline (PBS). The cells were then resuspended in $400 \mu \mathrm{l}$ of binding buffer and divided into two tubes, adding $5 \mu \mathrm{l}$ of Annexin V-FITC to one tube according to the manufacturer's instructions. After incubation for $15 \mathrm{~min}$ at room temperature in the dark, $10 \mu 1$ of PI was added. Finally, the stained cells were examined by BD FACSCalibur flow cytometer equipped with CellQuest software (both from BD Biosciences, Franklin Lakes, NJ, USA).

Cell cycle arrest assay. Following treatment with matrine or LY294002 under the same conditions as the apoptosis assay, the cells were resuspended at a concentration of $1.5 \times 10^{5}$ cells $/ \mathrm{ml}$. Subsequently, the cells were fixed in $70 \%$ ethanol and stored overnight at $4^{\circ} \mathrm{C}$. The fixed cells were suspended in PI containing RNase $\mathrm{A}$, and then incubated at $37^{\circ} \mathrm{C}$ for $1 \mathrm{~h}$. DNA content was analyzed using a fluorescence-activated cell sorter and CellQuest software.

Western blot analysis. Following treatment with matrine (1.5 or $2.5 \mathrm{~g} / \mathrm{l})$ and/or LY294002, cells were washed twice with ice-cold PBS, lysed with RIPA lysis buffer and complete protease inhibitor for $30 \mathrm{~min}$ on ice, and then cleared by centrifugation at $12,000 \mathrm{rpm}$ at $4^{\circ} \mathrm{C}$ for another $30 \mathrm{~min}$. The total protein concentration in the extracts was assessed utilizing a BCA protein assay kit (Beyotime Biotechnology, Shanghai, China). Equal amounts of protein were separated by SDS-PAGE and transferred to polyvinylidene fluoride (PVDF) membranes (Millipore, Billerica, MA, USA). The membranes were blocked with $5 \%$ BSA or non-fat dry milk in Tris-buffered saline and Tween-20 (TBST), for $1 \mathrm{~h}$ and then probed with antibodies against Akt (9272), p-Akt (2965), P27 (2552), CDK4 (12790), Bim (2933) (1:1,000; Cell Signaling Technology); CDK2 (ab32147), Bax (ab32503), Bcl-2 (ab59348) and p-FoxO3a (ab154786) (1:1,000; Abcam) and FoxO3a (GTX79072) (1:500; GeneTex) at $4^{\circ} \mathrm{C}$ with gentle shaking overnight. The membranes were then incubated with HRP-conjugated anti-rabbit or anti-mouse secondary antibodies (1:20,000; Cell Signaling Technology, Beverly, MA, USA) for $1 \mathrm{~h}$ at room temperature followed by detection using a chemiluminescence ECL kit (Millipore).

RNA isolation and semi-quantitative RT-PCR. According to the manufacturer's instructions, total RNA was extracted from treated cell samples using TRIzol reagent, before being reverse-transcribed into cDNA using PrimeScript RT Master Mix (both from Takara, Dalian, China). GAPDH was used as an internal control. RT-PCR and data collection were performed on the CFX96 Real-Time PCR Detection System (Bio-Rad, Hercules, CA, USA). The results were calculated using the $2^{-\Delta \Delta C t}$ method. All results are expressed as the mean \pm SEM of three independent experiments. Primers were synthesized by Shenggong Biological Engineering Co., Ltd. (Shanghai, China). The results were normalized with the value detected for GAPDH. Real-time PCR primers were as follows: FoxO3a forward (5'-GCACCTCATCCTTCTTTCAA-3') and reverse (5'-CATGCGTCACCATCTCTTTT-3'); PI3K forward (5'-AAAGGCGGCTTGAAAGGT-3') and reverse (5'-GACGATCTCCAATTCCCAAA-3'); and GAPDH forward (5'-TGGTCGTATTGGGCGCCTGGT-3') and reverse (5'-TCGCTCCTGGAAGATGGTGA-3').

Statistical analysis. Statistical analyses were performed using the SPSS software package (version 19.0) and GraphPad Prism 
A

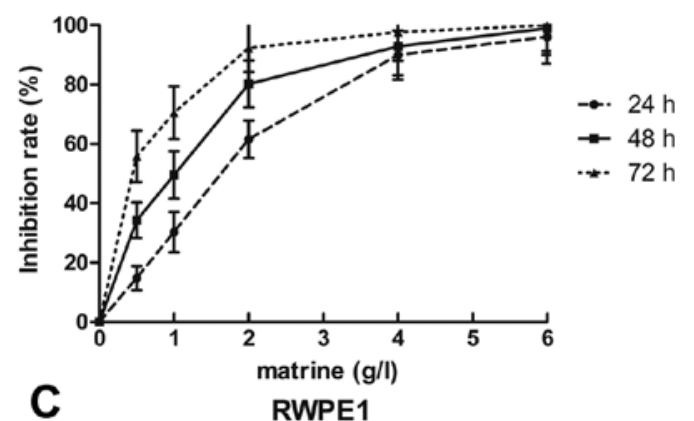

C

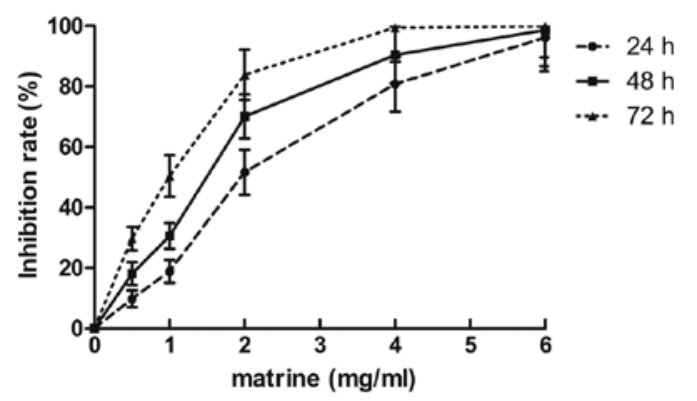

B

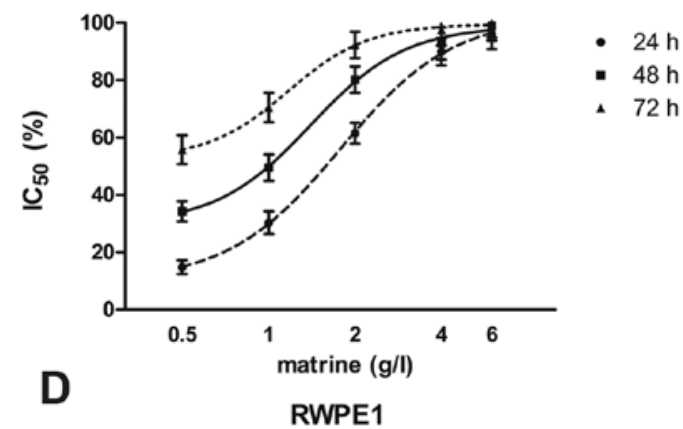

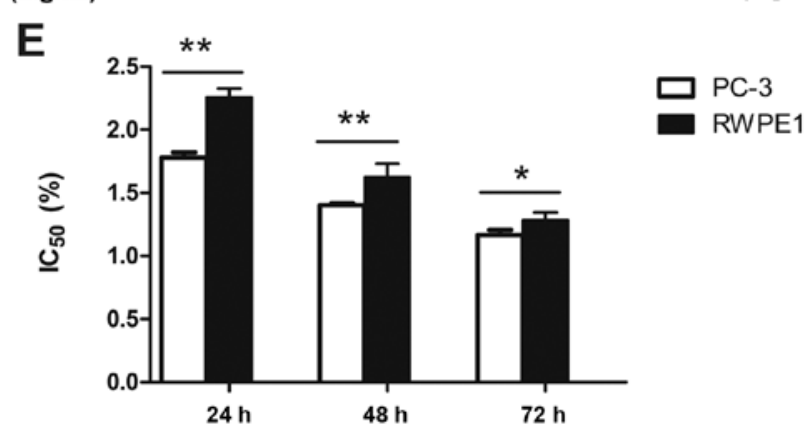

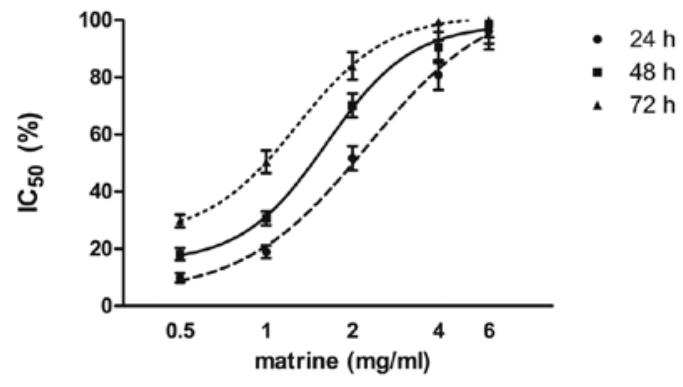

Figure 1. Matrine inhibits the proliferation of prostate cancer cells. (A and C) Plots of the rates of growth inhibition with increasing concentrations of matrine for increasing time periods in prostate cancer (A) PC-3 and prostate epithelial (C) RWPE1 cells. (B and D) Plots of the $\mathrm{IC}_{50}$ values in different prostate cell lines incubated for increasing time periods in $\mathrm{A}$ and $\mathrm{C}$. (E) The $\mathrm{IC}_{50}$ values of the two cell lines achieved a statistically significant difference. The sensitivity of matrine in the PC-3 cells was higher than that in the RWPE1 cells. ${ }^{*} \mathrm{p}<0.05,{ }^{* *} \mathrm{p}<0.01$.

Software. Data are expressed as the mean \pm standard deviation (SD) and analyzed using one-way ANOVA. All of the p-values were two-sided and $\mathrm{p}<0.05$ was considered to indicate a statistically significant result.

\section{Results}

Matrine effectively inhibits the proliferation of prostate cancer cells in a concentration- and time-dependent manner. The proliferation of prostate cancer cells was assessed using the MTS assay. Matrine inhibited the proliferation of PC-3 cells, with an $\mathrm{IC}_{50}$ value of $1.78 \pm 0.023 \mathrm{~g} / \mathrm{l}$ at $24 \mathrm{~h}, 1.40 \pm 0.008 \mathrm{~g} / \mathrm{l}$ at $48 \mathrm{~h}$ and $1.17 \pm 0.023 \mathrm{~g} / 1$ at $72 \mathrm{~h}$ (Fig. 1A and B). Therefore, the concentration of $1.5 \mathrm{~g} / \mathrm{l}$ was appropriate for the subsequent experiments. To determine whether matrine affects the proliferation of RWPE1, an MTS assay was performed following matrine treatment at various concentrations. As shown in Fig. 1C and D, similar proliferation inhibition was observed in the RWPE1 cell line. Matrine inhibited the proliferation of RWPE1 cells, with an $\mathrm{IC}_{50}$ value of $2.26 \pm 0.039 \mathrm{~g} / 1$ at $24 \mathrm{~h}$, $1.63 \pm 0.061 \mathrm{~g} / 1$ at $48 \mathrm{~h}$ and of $1.28 \pm 0.053 \mathrm{~g} / 1$ at $72 \mathrm{~h}$. The sensitivity of matrine in the PC-3 cells was higher than that in the RWPE1 cells (Fig. 1E).

Matrine triggers prostate cancer cell cycle arrest at the $G_{0} / G_{l}$ phase by upregulating $P 27$ and downregulating $C D K 4$ and $C D K 2$. To further determine whether the antiproliferation effect of matrine on prostate cancer cells was due to cell cycle arrest, cultured prostate cancer cells were treated with matrine, LY294002 or a combination of the two for flow cytometric analysis. As shown in Fig. 2A-D, matrine treatment resulted in an appreciable arrest of PC-3 (Fig. 2A and C) and RWPE1 cells (Fig. $2 B$ and D) in the $G_{0} / G_{1}$ phase of the cell cycle at 74.72 and $71.35 \%$, respectively, after $48 \mathrm{~h}$ of treatment compared to the untreated controls (55.87 and $58.58 \%$, respectively). The decrease in the percentage of cells in the $\mathrm{S}$ and $\mathrm{G}_{2} / \mathrm{M}$ phases of the cell cycle was accompanied by a concomitant increase in the $\mathrm{G}_{0} / \mathrm{G}_{1}$ cell population. Matrine combined with LY294002 treatment of PC-3 (Fig. 2A and C) and RWPE1 cells (Fig. 2B and D) induced 83.25 and $79.29 \%$ arrest in the $\mathrm{G}_{0} / \mathrm{G}_{1}$ phase of the cell cycle, respectively, compared to the LY294002 control (71.03 and 70.14\%, respectively). Compared 
A

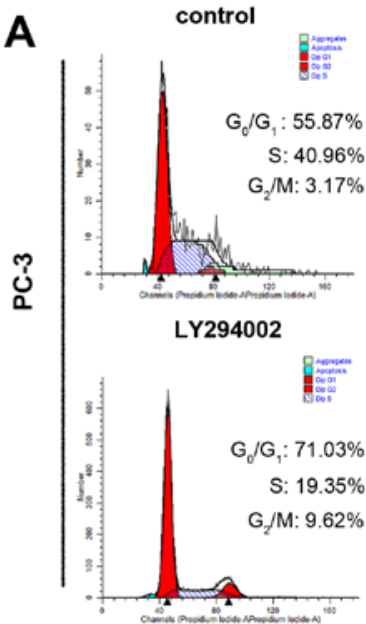

B

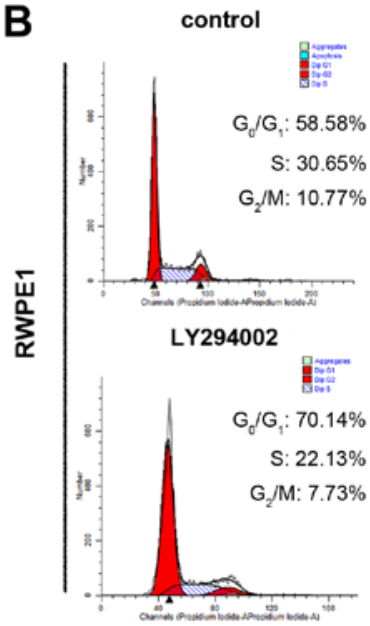

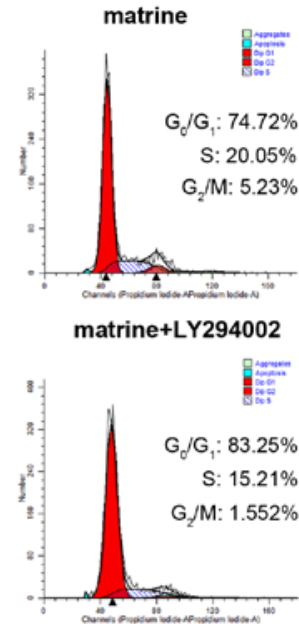

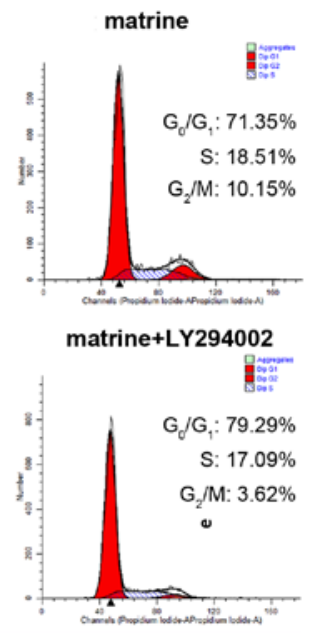

C

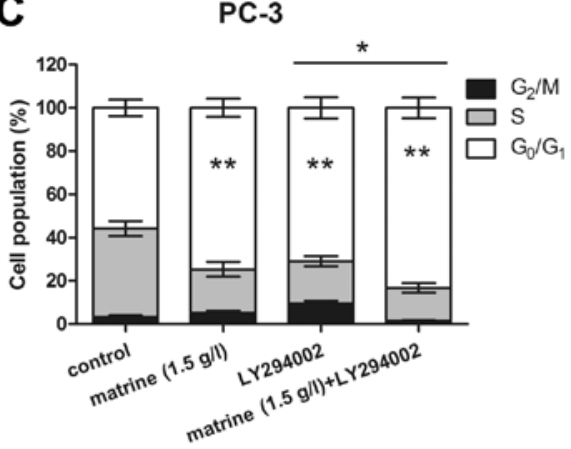

D
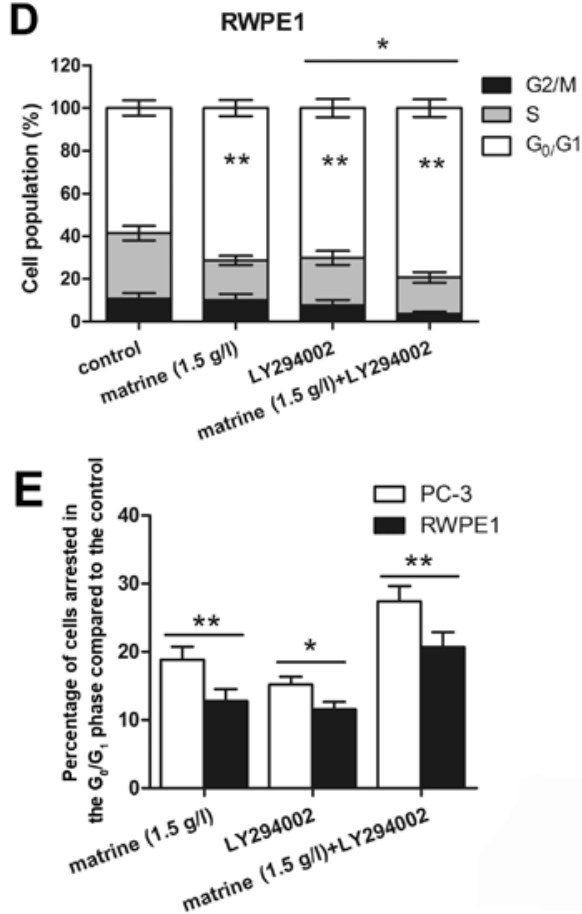

Figure 2. Effects of matrine on prostate cancer cell cycle arrest and apoptosis. (A) PC-3 and (B) RWPE1 cells were treated with matrine alone, LY294002 alone or a combination of the two. (C and D) The percentage of cells in $\mathrm{G}_{0} / \mathrm{G}_{1}, \mathrm{G}_{2} / \mathrm{M}$ and $\mathrm{S}$ phase cell cycle arrest was calculated. (E) Compared to the control, the increasing percentage of PC- 3 cells arrested in the $\mathrm{G}_{0} / \mathrm{G}_{1}$ phase was higher than that in the RWPE1 cells. " $\mathrm{p}<0.05,{ }^{* *} \mathrm{p}<0.01$.

to the control, the increasing percentage of cell arrest in the $\mathrm{G}_{0} / \mathrm{G}_{1}$ phase in the PC-3 cells was higher than that in the RWPE1 cells (Fig. 2E).

We assessed the effect of matrine on the expression of $\mathrm{P} 27$, CDK2 and CDK4, to determine whether matrine-induced cell cycle arrest of prostate cancer cells was dependent on the regulation of P27, CDK2 and CDK4. The expression levels of CDK2 and CDK4 were decreased in the PC-3 and RWPE1 cell lines after treatment with matrine (Fig. 3A-G). Notably, activation of P27 in cells was accompanied by a parallel decrease in the expression of CDK2 and CDK4. This was particularly evident when compared to cells treated with LY294002, in which matrine triggered prostate cancer cell cycle arrest at the $G_{0} / G_{1}$ phase by upregulating P27 and downregulating CDK4 and CDK2 relative to the protein expression of the PC-3 cells compared to the RWPE1 cells (Fig. 3H-K). The increased expression level of P27 and decreased expression levels of CDK4 and CDK2 in the PC-3 cells were higher than those in the RWPE1 cells.

Matrine induces cell apoptosis by increasing Bim and Bax and decreasing Bcl-2 protein levels in prostate cancer cell lines. To gain further insight into the dynamic progression from apoptosis to eventual cell death induced by matrine, Annexin V-FITC/PI double staining was used to assess the cell population undergoing apoptosis after treatment with matrine, LY294002 or a combination of the two for $48 \mathrm{~h}$. The percentage of apoptotic cells, including early (Annexin $\mathrm{V}^{+} / \mathrm{PI}^{-}$) and late $\left(\right.$Annexin $\mathrm{V}^{+} / \mathrm{PI}^{+}$) apoptotic cells, was $20.11 \%$ in the PC-3 cells and $15.55 \%$ in the RWPE1 cells after treatment with matrine (Fig. 4A-D). However, $<5 \%$ of the untreated cells underwent apoptosis under the same conditions (Fig. 4A-D). PC-3 and RWPE1 cells treated with matrine combined with LY294002 resulted in $25.88 \%$ cell apoptosis in the PC-3 cells and $18.88 \%$ in the RWPE1 cells, compared to 3.11 and $6.89 \%$, respectively, with LY294002 treatment only (Fig. 4A-D). Compared to the RWPE1 cells, the total apoptosis in the PC-3 cells was higher (Fig. 4E).

To further demonstrate that matrine induced cell apoptosis in prostate cancer cells, the proteins Bim, Bax and Bcl-2 were studied. Bim can neutralize pro-survival members such as Bcl-2 and activate Bax, which can finally induce apoptosis. The prostate cancer cell line PC-3 expressed a high Bcl-2 and low Bax level, but the level of Bcl-2 decreased while the level 
A
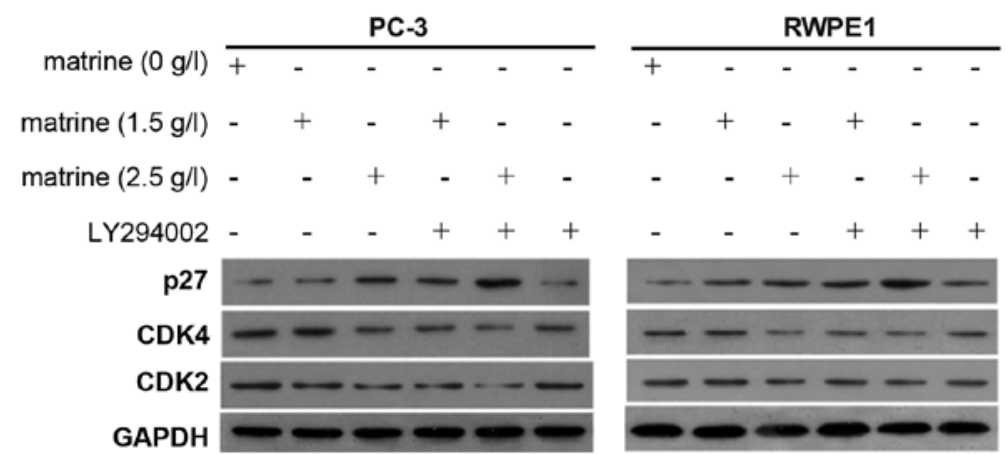

B

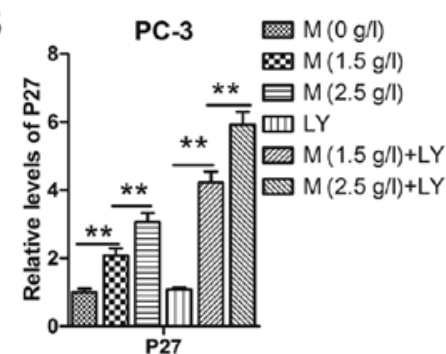

E

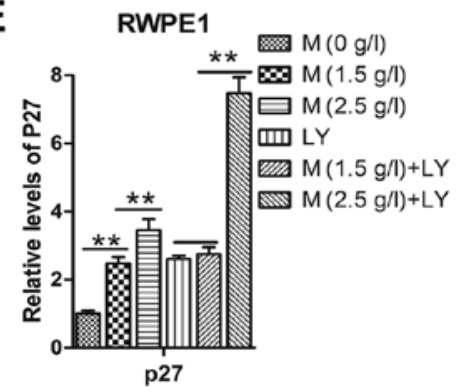

H

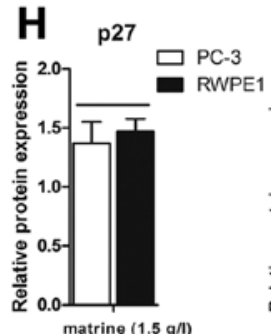

matrine $(1.5 \mathrm{~g} / \mathrm{l})$
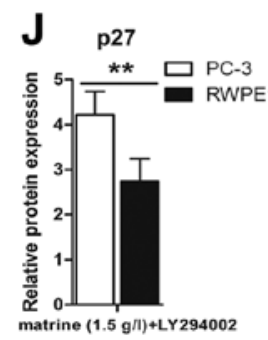

CDK4

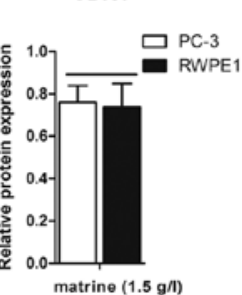

CDK4

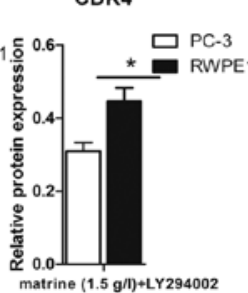

C

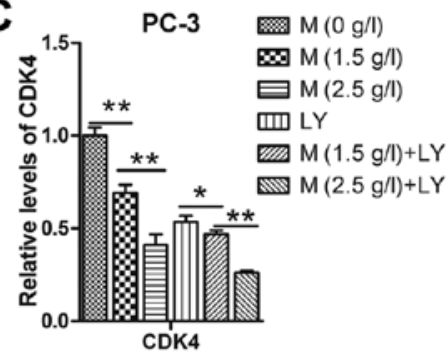

$\mathbf{F}$
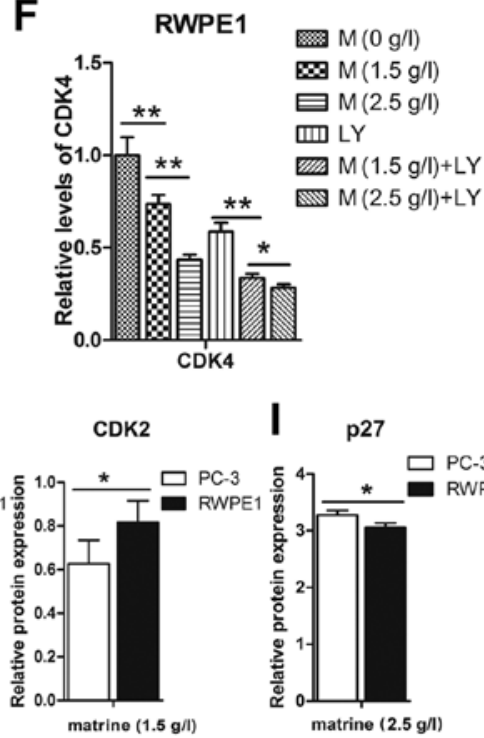

CDK2

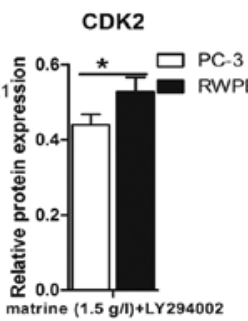

I p27

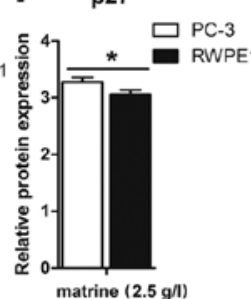

K $\quad$ p27

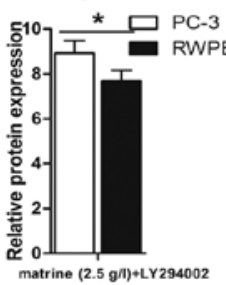

D

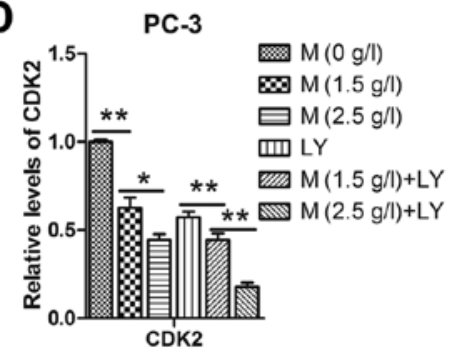

G
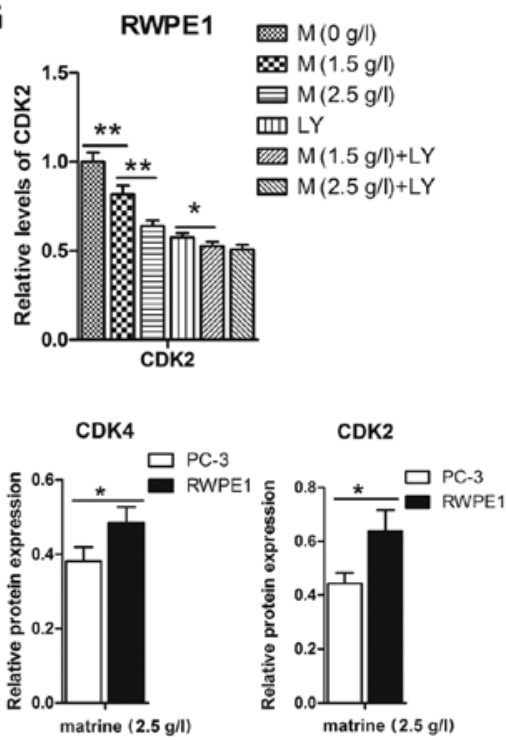

CDK4

CDK2
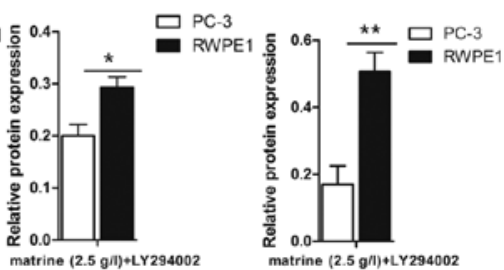

Figure 3. P27, CDK4 and CDK2 protein levels after treatment. (A) The protein level of P27 was increased in the PC-3 and RWPE1 cells after treatment with matrine and/or LY294002. Activation of P27 was accompanied by a parallel decrease in the expression levels of CDK4 and CDK2. (B-G) The quantification of the protein levels in A. (H-K) The protein levels in the PC-3 cells compared to the RWPE1 cells as determined in A; ${ }^{*} \mathrm{p}<0.05$, ${ }^{* *} \mathrm{p}<0.01$. M, matrine; LY, LY294002.

of Bax and Bim increased under the effect of matrine (Fig. 5A). Thus the ratio of the $\mathrm{Bcl}-2 / \mathrm{Bax}$ (Fig. 5B and $\mathrm{D}$ ) protein was markedly downregulated, which corresponded to the upregulation of Bim (Fig. 5A, C and E). For further verification, cells were treated with matrine combined with LY294002 to confirm that Bim may contribute, at least in part, to the induction of prostate cancer cell apoptosis by regulating the Bax and $\mathrm{Bcl}-2$ relative protein expression in $\mathrm{PC}-3$ cells compared to RWPE1 cells (Fig. 5F-I).The increased expression of Bim and the ratio of $\mathrm{Bax} / \mathrm{Bcl}-2$ in the PC-3 cells were higher than those in the RWPE1 cells.

Matrine suppresses the activity of the PI3K/Akt signaling pathway in prostate cancer cells. Activation of the Akt 

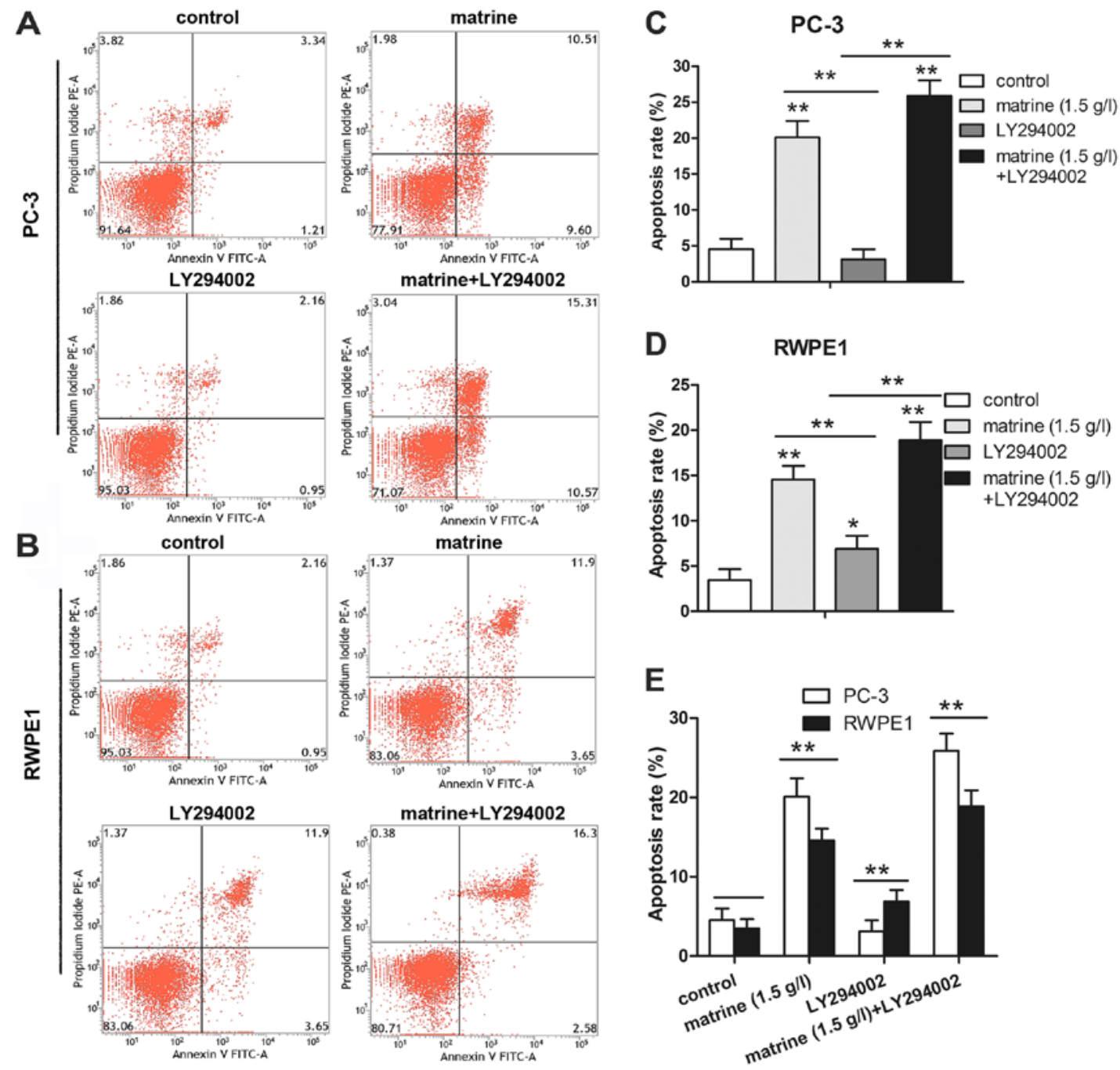

Figure 4. Effects of matrine on prostate cancer cell apoptosis. (A) PC-3 and (B) RWPE1 cells were treated with matrine alone, LY294002 alone or a combination of the two for $48 \mathrm{~h}$, and were then subjected to Annexin V/PI apoptosis assay. (C and D) The percentage of total apoptosis was calculated. (E) The total apoptotic cells of the PC-3 cell line compared to the RWPE1 cell line. ${ }^{*}<<0.05,{ }^{* *} \mathrm{p}<0.01$.

signaling pathway plays a critical role through which cancer cells promote cell survival. We were therefore interested in determining whether matrine treatment has an effect on the Akt pathway. The expression levels of p-Akt and Akt were decreased after treatment with matrine for $48 \mathrm{~h}$ (Fig. 6A). To further confirm this finding, LY294002 was used to treat the cells for $1 \mathrm{~h}$ prior to matrine treatment. As shown in Fig. 6B and $\mathrm{C}$, and $\mathrm{F}$ and $\mathrm{G}$ the expression levels of $\mathrm{p}-\mathrm{Akt}$ and Akt were decreased after treatment with matrine and LY294002 compared to the matrine- or the LY294002-only group. A previous study demonstrated that an increase in p-Akt induced increased p-FoxO3a and its dysregulation (15). To determine whether matrine targets the expression of FoxO3a and its phosphorylation in prostate cancer cells, we determined the expression of FoxO3a and p-FoxO3a at the transcriptional (Fig. 7B and D) and translational levels (Fig. 6D and E, and 6H and I). The decreased expression levels of Akt/p-Akt and increased levels of FoxO3a/p-FoxO3a in the PC-3 cells were more obvious than in the RWPE1 cells (Fig. 6J-M). Furthermore, we also detected the expression of PI3K at the transcriptional level in the two prostate cell lines (Fig. 7A and C). The increase in the mRNA levels of
FoxO3a in the PC-3 cells was higher than that in the RWPE1 cells, but PI3K was not (Fig. 7E and F). Unfortunately, the exact mechanism causing the different transcriptional and translational levels remains unclear. However, matrine treatment resulted in an increase in FoxO3a and a decrease in p-FoxO3a and PI3K. Furthermore, LY294002 enhanced the effect of matrine, increasing FoxO3a with a concomitant decrease in p-FoxO3a via the PI3K/Akt signaling pathway.

\section{Discussion}

Our previous studies showed that matrine could be considered as a potential candidate for the treatment of prostate cancer (16). However, the exact underlying mechanisms of the effect of matrine on the inhibition of cancer cell growth are not fully understood. The results of the present study demonstrated that matrine effectively inhibited the proliferation of PC-3 and RWPE1 cells, which was associated with cell cycle arrest and apoptosis. Matrine decreased cell cycle progression by promoting a $\mathrm{G}_{0} / \mathrm{G}_{1}$ phase block, the effects of which were accompanied by the upregulation of the level of P27 and the downregulation of the levels of CDK4 and CDK2 proteins. 
A

\begin{tabular}{rllllll} 
A & \multicolumn{7}{c}{ PC-3 } \\
\cline { 2 - 6 } matrine $(0 \mathrm{~g} / \mathrm{l})$ & + & - & - & - & - & - \\
matrine $(1.5 \mathrm{~g} / \mathrm{l})$ & - & + & - & + & - & - \\
matrine $(2.5 \mathrm{~g} / \mathrm{l})$ & - & - & + & - & + & - \\
LY294002 - & - & - & + & + & +
\end{tabular}

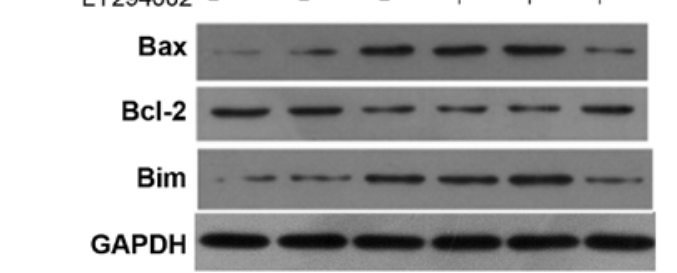

B

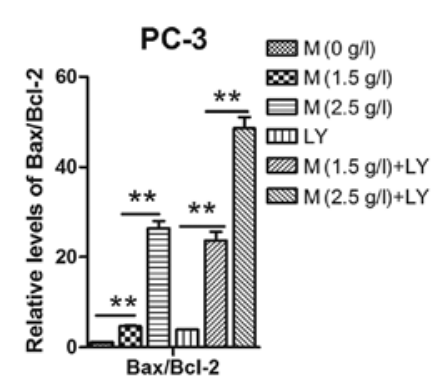

D
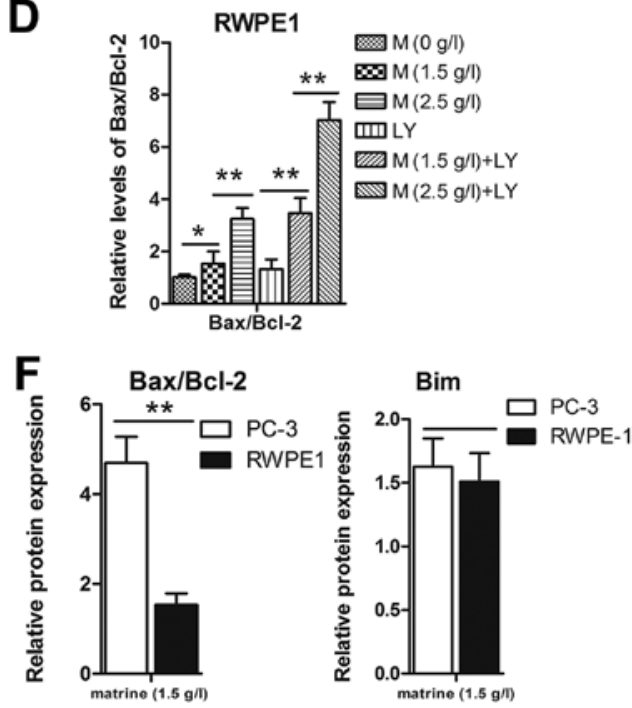

H Bax/Bcl-2
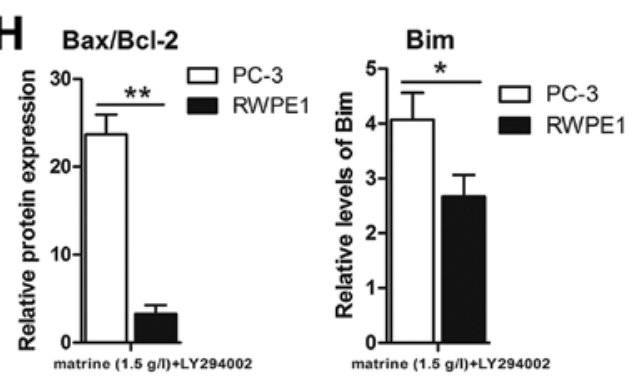

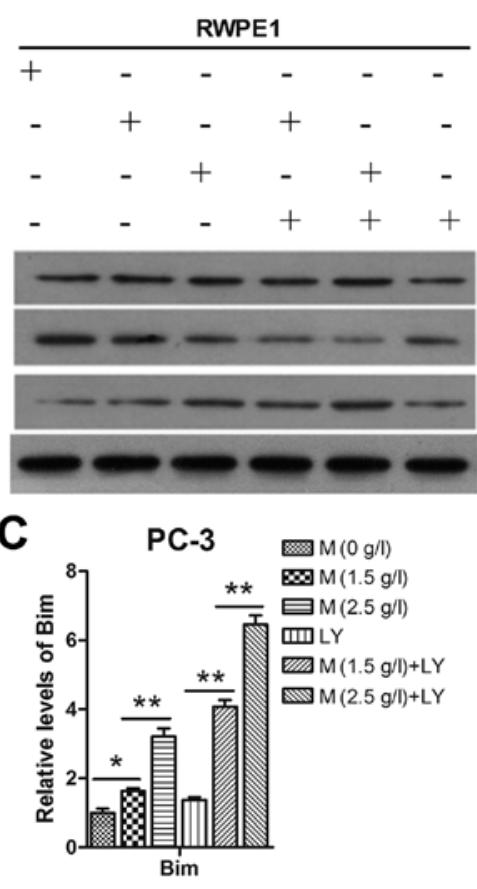

$\mathbf{E}$
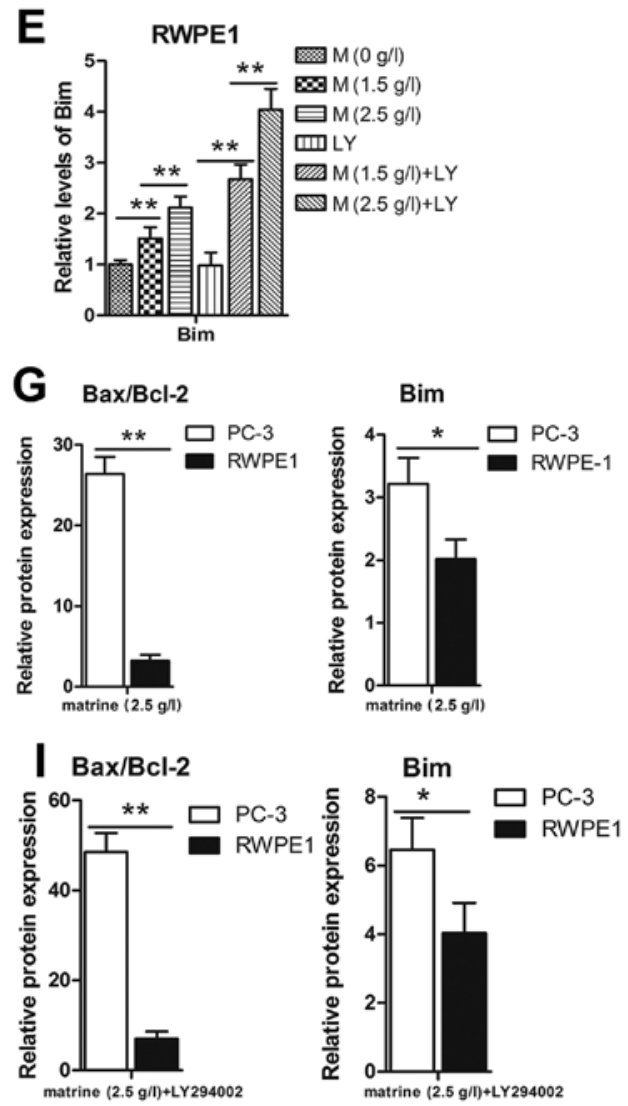

Figure 5. Bax, Bcl-2 and Bim protein levels after treatment. (A) The protein levels of Bax and Bim were increased while the protein level of Bcl-2 was decreased in the PC-3 and RWPE1 cells after treatment with matrine and/or LY294002. (B-E) The quantification of the protein levels in A. (F-I) The level of Bim and Bax/Bcl-2 ratio in the PC-3 cells compared to the RWPE1 cells as determined in A. * $<<0.05,{ }^{* *} \mathrm{p}<0.01$. M, matrine; LY, LY294002.

Concomitantly, matrine induced cell apoptosis as evidenced by the Bim, Bax and Bcl-2 protein level analysis. Our data also suggested that the proliferation of tumor cell suppression by matrine was linked to the inhibition of PI3K/Akt and FoxO3a activation. In the present study,LY294002 was used as a positive control since it has demonstrated antiproliferation properties in a variety of cell types and significantly downregulates
FoxO3a phosphorylation (17). To the best of our knowledge, this is the first study demonstrating the involvement of the Akt and FoxO3a signaling pathways in matrine-mediated prostate cancer suppression.

The PI3K/Akt signaling pathway is activated in various human cancers, including prostate cancer $(18,19)$. Decreased PTEN expression and loss of heterozygosity have been observed 
A

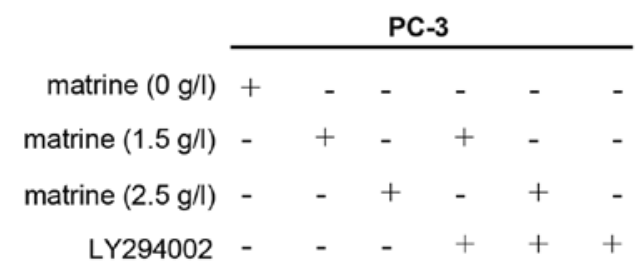

Akt

p-Akt (308)

FoxO3a

p-FoxO3a (253)

GAPDH

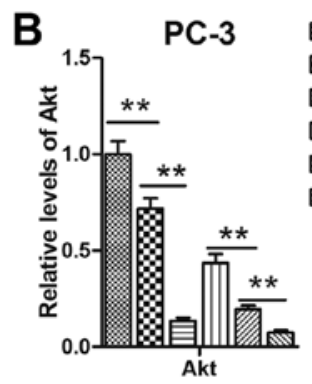

E
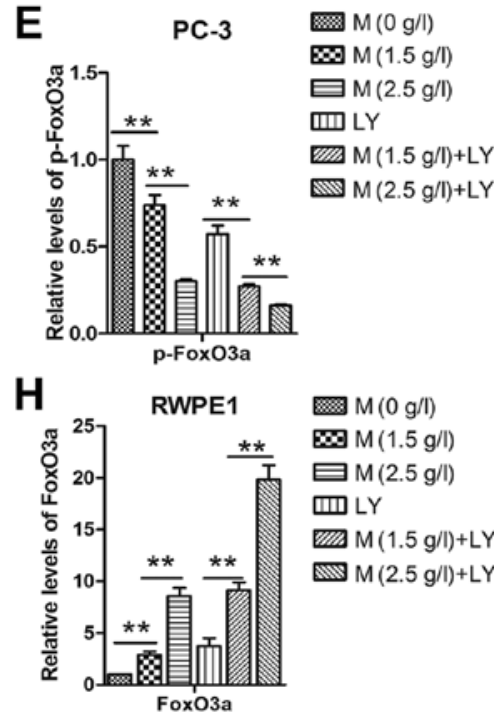

$\mathbf{K}$
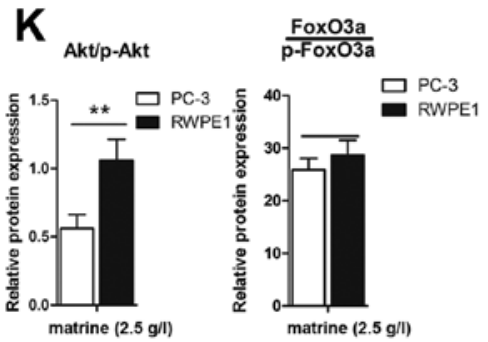
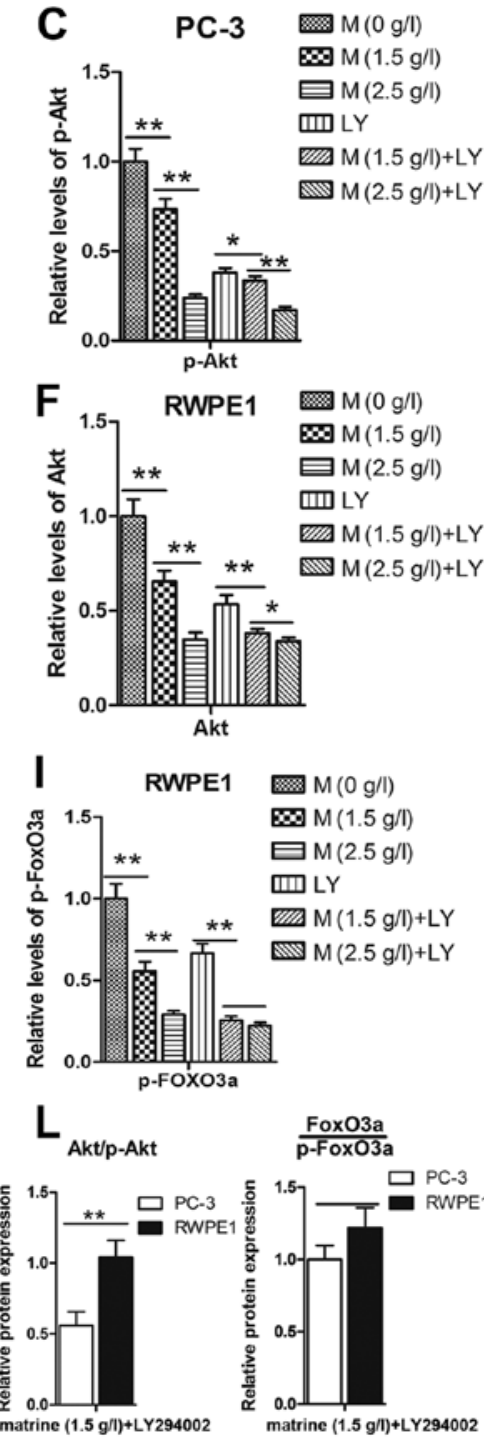
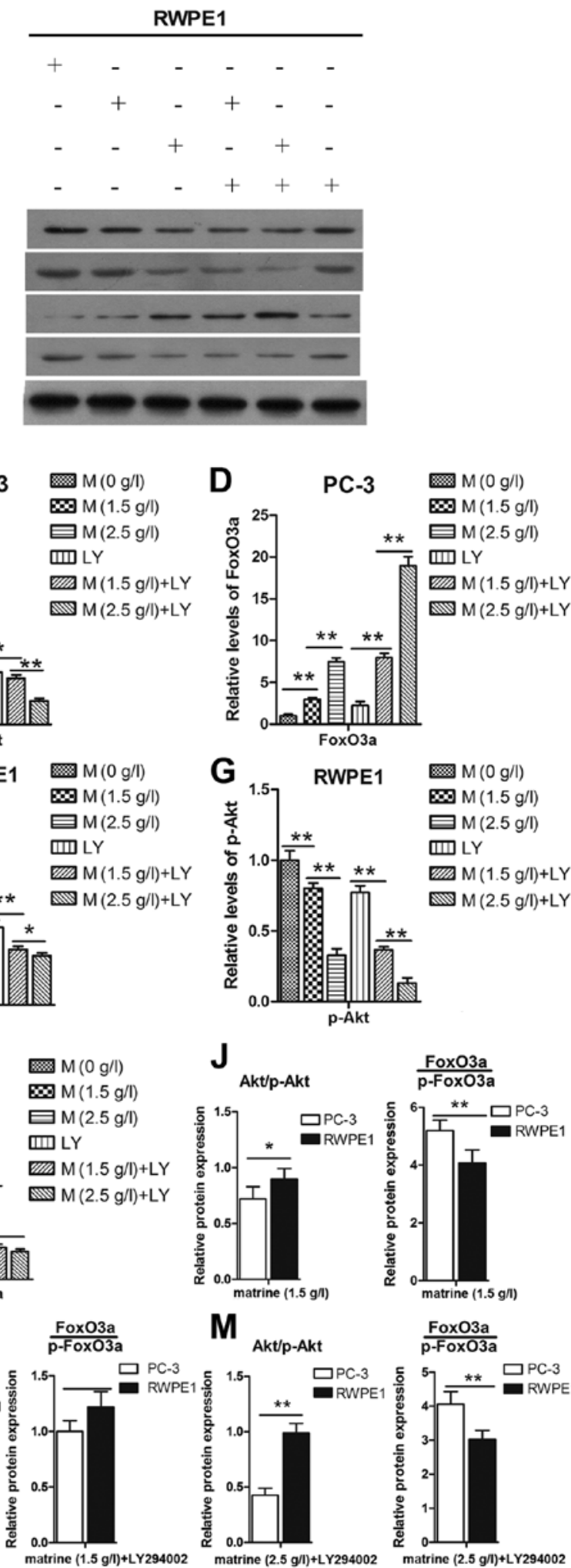

FoxO3a

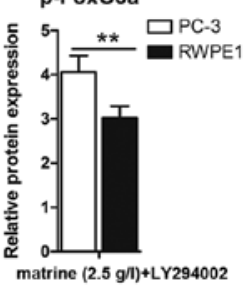

Figure 6. Matrine suppresses the activity of the Akt signaling pathway in prostate cancer cells. (A) Cells were treated with matrine, LY294002 alone or a combination of the two for $48 \mathrm{~h}$, and the expression levels of p-Akt, Akt, FoxO3a and p-FoxO3a were assessed by western blotting. (B-I) The quantification of the levels in A. (J-M) The ratios Akt/p-Akt and FoxO3a/p-FoxO3a in the PC-3 cells compared to the RWPE1 cells as determined in A. " $\mathrm{p}<0.05,{ }^{* *} \mathrm{p}<0.01$. M, matrine; LY, LY294002.

to cause hyperactive Akt in human prostate cancer (20). Several mechanisms involved in the overall responses of matrine in the inhibition of growth and induction of apoptosis in cancer or normal cells have been reported $(12,21)$. Consistent with this, our results demonstrated that activation of FoxO3a was also implicated in the effect of matrine on the regulation of the PI3K/Akt signaling pathway. FoxO3a plays an important role in multiple cellular processes involving cell cycle arrest, cell death, DNA damage repair, stress resistance and metabolism, and is a vital regulation point of the downstream PI3K/Akt 
A

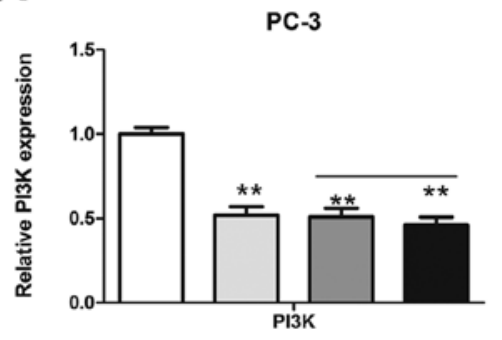

C

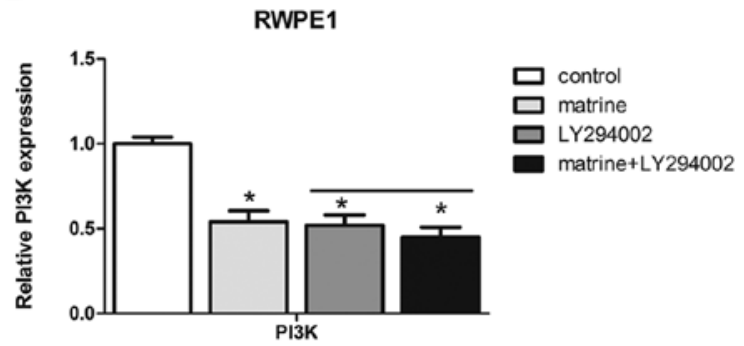

E
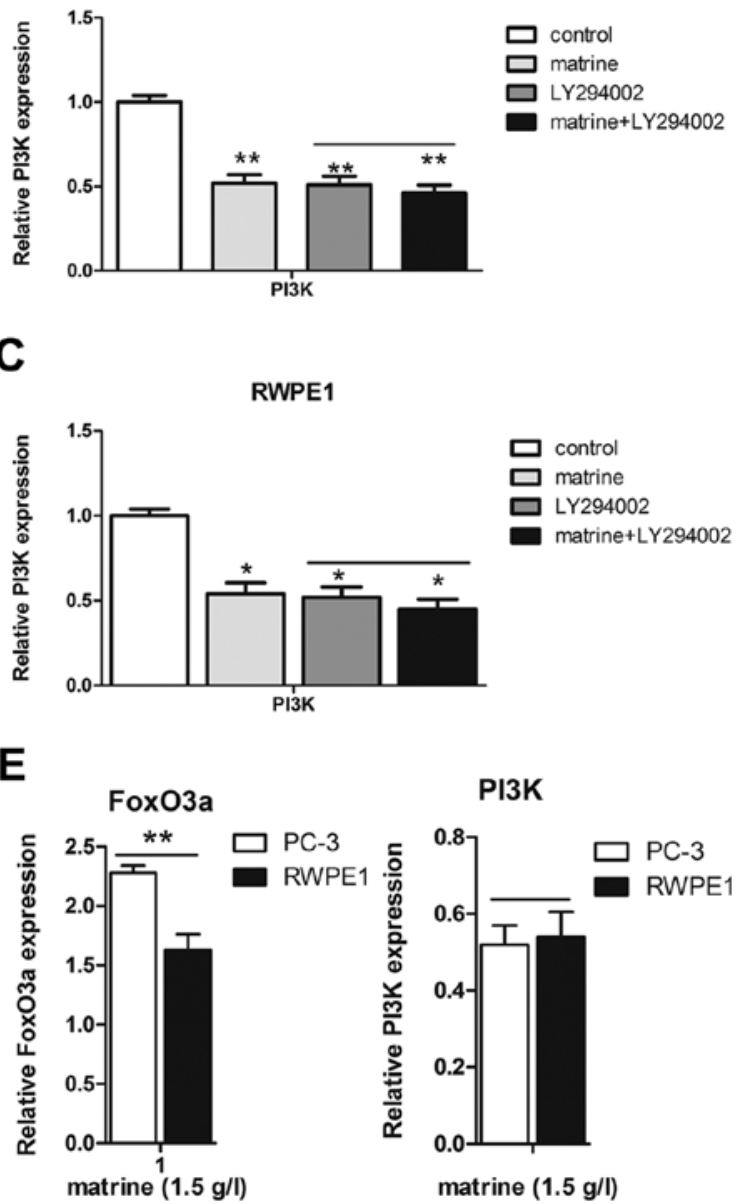

B

D

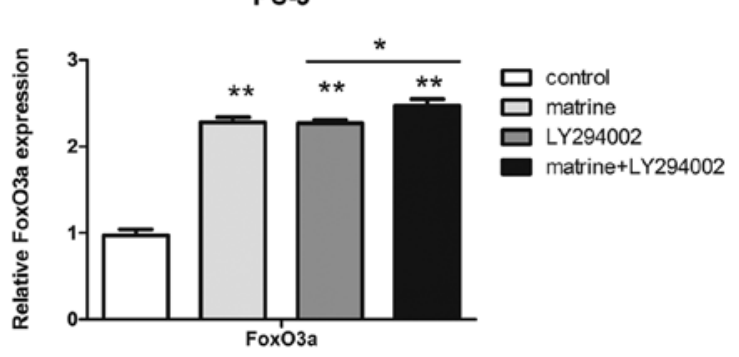

RWPE1

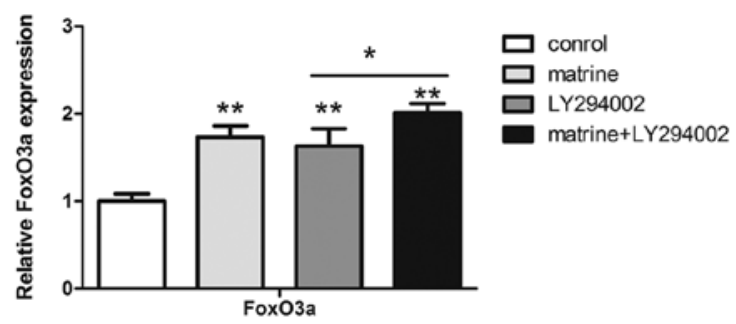

$\mathbf{F}$

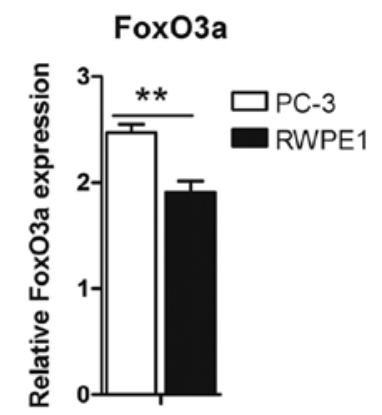

matrine $(1.5 \mathrm{~g} / \mathrm{l})+\mathrm{LY} 294002$

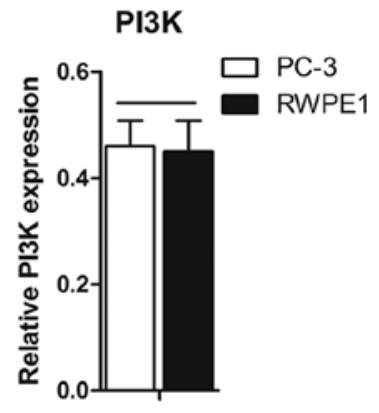

matrine $(1.5 \mathrm{~g} / \mathrm{l})+\mathrm{LY} 294002$

Figure 7. (A-D) FoxO3a and PI3K expression levels compared with the controls in (A and B) PC-3 and (C and D) RWPE1 cells as determined by RT-PCR. FoxO3a was upregulated while PI3K was downregulated in the matrine- and/or LY294002-treated group compared to the control group. (E and F) The mRNA levels of FoxO3a and PI3K in the PC-3 cells compared to the RWPE1 cells. ${ }^{\mathrm{p}}<0.05,{ }^{* *} \mathrm{p}<0.01$.

signaling pathway (5). Persistently activated Akt-mediated phosphorylation of FoxO3a is known to be associated with 14-3-3 protein, thereby leading to the transport of FoxO3a out of the nucleus and its retention in the cytoplasm, thus, preventing the transcriptional activity of FoxO3a (20). We detected the expression of FoxO3a at the translational level to verify whether the inhibition of p-Akt by matrine led to the retention of FoxO3a and sequentially increased the transcription of the downstream target genes of FoxO3a such as Bim and P27. Our results indicated that the levels of p-FoxO3a were decreased after matrine intake, resulting in increased levels of Bim and P27.

To date, there have been two major pro-apoptosis pathways: the mitochondrial (intrinsic pathway) and the death receptor pathway (extrinsic pathway) $(22,23)$. In the intrinsic pathway, apoptosis is controlled by a balance between the pro-apoptotic (Bax, Bak, Bim and Bad) and anti-apoptotic (Bcl-2 and Bcl-xL) members of the Bcl-2 family (24). Bim induces mitochondrial outer membrane permeability to release cytochrome $c$ during apoptosis, neutralizes pro-survival members such as Bcl-2 and activates Bax (25). Consistent with this, our data revealed that Bim was upregulated after matrine-mediated decreased phosphorylation of p-Akt (Thr308) and p-FoxO3a (Ser253), thereby inducing increased levels of Bax and decreased levels of Bcl-2. Previous studies demonstrated that the loss of mitochondrial membrane potential cannot only lead to the release of cytochrome $c$, but also subsequent activation of caspases (26). Unfortunately, the present study did not clarify our understanding of caspases, however, our findings revealed that Bim may contribute, at least in part, to the induction of prostate cancer cell apoptosis by matrine. P27 from the Cip/Kip family is a well-defined substrate for the ubiquitin ligase activity of SKP2/CUL1/F-box (SCF) complex (27), and plays a central role in restraining the $G_{1}$ phase initiation and $\mathrm{G}_{1} / \mathrm{S}$ transition (28). The upregulation of P27, as shown in the present study at the protein level in the matrine intake group, is consistent with the low levels of P27 in the control group. A similar result was obtained with LY294002 treatment alone and in combination with matrine. In the past, activation of the PI3K/Akt pathway was implicated in the regulation of P27 expression in diverse cell types (29). Collectively, these results suggest that a $G_{0} / G_{1}$ phase arrest of the cell cycle following inhibition of p-Akt by matrine can be attributed to a significant increase in P27 protein expression in prostate cancer.

In conclusion, the data presented here demonstrated that matrine treatment in prostate cancer can activate FoxO3a and that its accumulation can induce the expression of downstream target proteins Bim and P27, resulting in cell cycle arrest at 
the $G_{0} / G_{1}$ phase and triggering apoptosis in prostate cancer. We also demonstrated a synergistic effect of matrine and LY294002 on prostate tumors. In light of the different effects of matrine on PC-3 and RWPE1 cells, a lack of in-depth research remains. However, these findings suggest that matrine could be used as a potential preventive agent in the management of castration-resistant prostate cancer in humans.

\section{Acknowledgements}

The present study was supported by the National Natural Science Foundation of China (nos. 81472382 and 81672550), the National Natural Science Foundation of China for Young Scientists Grant (no. 81101947), the Guangdong Province Natural Science Foundation (no. 2014A030313079), the Fundamental Research Funds for the Central Universities (no. 14ykpy19), the Guangdong Province Science and Technology for Social Development Project (nos. 2013B0 21800107 and 2013B021800095), the 2015 Guangzhou City Scientific Research Projects (no. 201510010298), and the International Science and Technology Cooperation Project of Guangdong Province Science and Technology Plan (no 2016A050502020).

\section{References}

1. Siegel RL, Miller KD and Jemal A: Cancer statistics, 2015. CA Cancer J Clin 65: 5-29, 2015.

2. Torre LA, Bray F, Siegel RL, Ferlay J, Lortet-Tieulent J and Jemal A: Global cancer statistics, 2012. CA Cancer J Clin 65: 87-108, 2015.

3. Fowke JH, McLerran DF, Gupta PC, He J, Shu XO, Ramadas K, Tsugane S, Inoue M, Tamakoshi A, Koh WP, et al: Associations of body mass index, smoking, and alcohol consumption with prostate cancer mortality in the Asia Cohort Consortium. Am J Epidemiol 182: 381-389, 2015.

4. Sarker D, Reid AHM, Yap TA and de Bono JS: Targeting the PI3K/AKT pathway for the treatment of prostate cancer. Clin Cancer Res 15: 4799-4805, 2009.

5. Shukla S: FOXO3a: A potential target in prostate cancer. Austin J Urol, p1, 2014.

6. Daitoku H, Sakamaki J and Fukamizu A: Regulation of FoxO transcription factors by acetylation and protein-protein interactions. Biochim Biophys Acta 1813: 1954-1960, 2011.

7. Arrendale A, Kim K, Choi JY, Li W, Geahlen RL and Borch RF: Synthesis of a phosphoserine mimetic prodrug with potent 14-3-3 protein inhibitory activity. Chem Biol 19: 764-771, 2012.

8. Rinner O, Mueller LN, Hubálek M, Müller M, Gstaiger M and Aebersold R: An integrated mass spectrometric and computational framework for the analysis of protein interaction networks. Nat Biotechnol 25: 345-352, 2007.

9. Wang W, You RL, Qin WJ, Hai LN, Fang MJ, Huang GH, Kang RX, Li MH, Qiao YF, Li JW, et al: Anti-tumor activities of active ingredients in Compound Kushen Injection. Acta Pharmacol Sin 36: 676-679, 2015.

10. Zhou Y, Wu Y, Deng L, Chen L, Zhao D, Lv L, Chen X, Man J, Wang Y, Shan H, et al: The alkaloid matrine of the root of Sophora flavescens prevents arrhythmogenic effect of ouabain. Phytomedicine 21: 931-935, 2014.
11. Guo B, Zhang T, Su J, Wang K and Li X: Oxymatrine targets EGFR $^{\text {p-Tyr845 }}$ and inhibits EGFR-related signaling pathways to suppress the proliferation and invasion of gastric cancer cells. Cancer Chemother Pharmacol 75: 353-363, 2015.

12. Xie M, He G, Wang R, Shi S, Chen J, Ye Y, Xie L, Yi X and Tang A: Matrine-induced apoptosis of human nasopharyngeal carcinoma cells via in vitro vascular endothelial growth factor-A/extracellular signal-regulated kinase1/2 pathway inactivation. Horm Metab Res 46: 556-560, 2014.

13. Zhang L, Wang T, Wen X, Wei Y, Peng X, Li H and Wei L: Effect of matrine on HeLa cell adhesion and migration. Eur J Pharmacol 563: 69-76, 2007.

14. Liu Y, Xu Y, Ji W, Li X, Sun B, Gao Q and Su C: Anti-tumor activities of matrine and oxymatrine: Literature review. Tumour Biol 35: 5111-5119, 2014.

15. Shukla S, Bhaskaran N, Babcook MA, Fu P, Maclennan GT and Gupta S: Apigenin inhibits prostate cancer progression in TRAMP mice via targeting PI3K/Akt/FoxO pathway. Carcinogenesis 35: 452-460, 2014.

16. Li Q, Lai Y, Wang C, Xu G, He Z, Shang X, Sun Y, Zhang F, Liu L and Huang H: Matrine inhibits the proliferation, invasion and migration of castration-resistant prostate cancer cells through regulation of the NF- $\mathrm{NB}$ signaling pathway. Oncol Rep 35: 375-381, 2016.

17. Wang D, Yang Y, Huang R, Zhang $Z$ and Lin X: Myostatin activates the ubiquitin-proteasome and autophagy-lysosome systems contributing to muscle wasting in chronic kidney disease. Oxid Med Cell Longev 2015: 684965, 2015.

18. Majumder PK and Sellers WR: Akt-regulated pathways in prostate cancer. Oncogene 24: 7465-7474, 2005.

19. Carnero A: The PKB/AKT pathway in cancer. Curr Pharm Des 16: 34-44, 2010.

20. Trotman LC, Alimonti A, Scaglioni PP, Koutcher JA, Cordon-Cardo C and Pandolfi PP: Identification of a tumour suppressor network opposing nuclear Akt function. Nature 441: 523-527, 2006

21. Zhang P, Wang Z, Chong T and Ji Z: Matrine inhibits proliferation and induces apoptosis of the androgen-independent prostate cancer cell line PC-3. Mol Med Rep 5: 783-787, 2012.

22. Yaoxian W, Hui Y, Yunyan Z, Yanqin L, Xin G and Xiaoke W: Emodin induces apoptosis of human cervical cancer hela cells via intrinsic mitochondrial and extrinsic death receptor pathway. Cancer Cell Int 13: 71, 2013.

23. Nam YJ, Mani K, Ashton AW, Peng CF, Krishnamurthy B, Hayakawa Y, Lee P, Korsmeyer SJ and Kitsis RN: Inhibition of both the extrinsic and intrinsic death pathways through nonhomotypic death-fold interactions. Mol Cell 15: 901-912, 2004.

24. Heath-Engel HM and Shore GC: Regulated targeting of Bax and Bak to intracellular membranes during apoptosis. Cell Death Differ 13: 1277-1280, 2006.

25. Desagher S and Martinou JC: Mitochondria as the central control point of apoptosis. Trends Cell Biol 10: 369-377, 2000.

26. Takuma K, Baba A and Matsuda T: Astrocyte apoptosis: Implications for neuroprotection. Prog Neurobiol 72: 111-127, 2004.

27. Morimoto M, Nishida T, Honda R and Yasuda H: Modification of cullin-1 by ubiquitin-like protein Nedd8 enhances the activity of $\mathrm{SCF}^{\mathrm{skp} 2}$ toward p27 ${ }^{\mathrm{kip} 1}$. Biochem Biophys Res Commun 270: 1093-1096, 2000.

28. Ray A, James MK, Larochelle S, Fisher RP and Blain SW: p27 $7^{\text {Kipl }}$ inhibits cyclin D-cyclin-dependent kinase 4 by two independent modes. Mol Cell Biol 29: 986-999, 2009.

29. Stahl M, Dijkers PF, Kops GJ, Lens SM, Coffer PJ, Burgering BM and Medema RH: The forkhead transcription factor FoxO regulates transcription of $\mathrm{p} 27^{K i p l}$ and $\mathrm{Bim}$ in response to IL-2. J Immunol 168: 5024-5031, 2002. 